\title{
Development of an Instrument for Chromosome Slide Preparation
}

\author{
KIYOMI YAMADA ${ }^{1)}$, KEN KAKINUMA ${ }^{2)}$, HIROE TATEYA ${ }^{3)}$ \\ AND CHIAKI MIYASAKA ${ }^{3)}$ \\ ${ }^{1)}$ Division of Genetics, Clinical Research Institute, National Medical \\ Center, Toyama 1-21-1, Shinjuku-ku, Tokyo 162 \\ ${ }^{2)}$ Products Development Division, Sakura Finetechnical Co., Ltd., \\ Honcho 3-1-9, Nihonbashi, Chuo-ku, Tokyo 103 \\ ${ }^{33}$ Medical Division, Engineering Department, Tiyoda Manufacturing Co., Ltd., \\ Imojiya 75-5, Koshoku-city, Nagano-ken 387
}

\begin{abstract}
Instrument development/Semi-automatic processor/Chromosome slides/Steam dry method/Automation cytogenetics
\end{abstract}

For cytogenetic analysis of chromosome abnormalities, we have developed an instrument which can produce semi-automatically chromosome slides for microscopic observation. This instrument has automatic slide supplyer and slide transfer system. Chromosome slides were obtained by the steam dry method; slides were sequentially exposed to different atmosphere controlled strictly in respect of temperature and humidity. Slides with well-spread chromosomes were obtained constantly in quality and rapidly in speed of 5 slides per minute. Precise controls of room temperature and humidity were attained by the use of 26 thermomodules. Accuracy of the controls was excellently high, showing a fiuctuation of $\pm 0.5^{\circ} \mathrm{C}$ in temperature and $\pm 3 \%$ in humidity for any setting in the use range. This instrument was proved to be very useful for rapid obtaining of a large number of chromosome slides with highly qualified metaphase spreads. This instrument will be utilized to assist the automation analysis system of chromosome abnormalities. Mechanism of chromosome spreading, problems in actual use, and future improvements were discussed.

\section{INTRODUCTION}

Chromosome abnormalities induced by radiation exposure have a dose-yield relationship. Therefore, the dosage of radiation exposed to a human body can be estimated from analysis of chromosome abnormalities in peripheral lymphocytes cultured in vitro. As a matter of fact, this biological radiation-dosimetry is particularly useful in case of accidentally exposed people. This method was established by experimental studies, and has been proved to be highly reliable from actual studies, for examples, of atomic bomb survivors in Hiroshima and Nagasaki and of Japanese fishermen exposed to fallout of radiation at Bikini coral islands ${ }^{1,2,3)}$.

In recent years, social interest from a standpoint of health care has been accumulated on the low-dose exposure of radiation and chemical substances in our living environment. Cytogenetic studies of chromosome abnormalities in somatic cells of certain industrial workers are necessary

山田清美：国立病院医療センター臨床研究部遺伝，東京都新宿区戸山1-21-1 $\overline{\mathbf{T}} 162$ 
for health administration and surveillance of environmental pollution. Experimental investigation of dose estimation and biological effects by the low-dose exposure has been in progress. However, biological dosimetry in humans using chromosome abnormalities as indicator is not easy particularly for the low-dose range in the actual practice of chromosome examination. In order to get a reliable estimate for the low-dose exposure by radiation, some thousands of dividing cells must be examined from a person microscopically. Automation of cell culturing and slide preparation, and automated analysis system of chromosome abnormalities are needed in such studies. Some investigators have made an attempt for automation of technical procedures $^{4,5,6)}$.

Since 1989, we have been concerned in development of an instrument which can produce rapidly a large number of microscopic slides with well-spread chromosomes suitable for analysis. Now we have a 2 nd trial product, and satisfactory results have been obtained in test studies. In the present study, we would like to introduce main characteristics of this instrument and to report results of chromosome spreading in the actual use of this instrument. Development of this instrument will help to perform a large-scale chromosome analysis in the low-dose exposure by using the computer-assisted automation system.

\section{RESULTS AND DISCUSSION}

\section{Analysis of environmental factors influencing upon chromsome slide preparation}

The most basic technique to get chromosome slides is the air dry method originally reported by Rothfels and Siminovitsch ${ }^{7}$. However, in Japan, it was not easy to obtain chromosome slides of good quality according to this method; chromosomes did not spread well, probably by environmental influences due to seasonal changes of the climate. Accordingly, modified methods were preferred in Japan. After the prevalence of the flame dry method, the steam dry method has been used in many laboratories since the middle of 1980's for the reason of producing more fine good bands on chromosomes by staining.

According to the steam dry method, slides are usually obtained in the manner as follows; a water-bath is placed in the box to make hot room temperature and high humidity. In the inside of the box, an aliquot of cell-suspended fixative is dropped on a clean slide in the upper air-zone and then, the slide is gradually dried up in the lower air-zone. Thus, we can get slides with well-spread chromosomes. However, skillful techniques and wide experience are demanded to obtain well-qualified slides constantly by overwhelming environmental influences. Hence, the method widely varies by investigators.

We performed preliminary studies for automation of slide preparation. Relatively precise data were obtained on biological and physical factors which influence upon slide preparation, by monitoring temperature and humidity changes in several check-points inside the box using measurement instruments and recorders. The following conditions were revealed necessary for producing well-spread chromosome slides: 1) Atmosphere just above the slide was $30-35^{\circ} \mathrm{C}$ temperature and $60-80 \%$ humidity. 2) Exposed time was for 10-12 seconds after dropping of cell-suspension, and then the slide had to move to atmosphere with low humidity to prevent 
over-spreading of chromosomes. 3) Slides were excellently clean and sloped in an angle of 5-15 degrees. 4) Volume of cell-suspension to drop was $20-30 \mu l$, in $10^{6}$ cells $/ \mathrm{ml}$ of concentration. 5) Slides were dried for 1-2 minutes with atmosphere of $30^{\circ} \mathrm{C}$ and $40-50 \%$ humidity. We tried to produce these conditions mechanically by excluding environmental influences, and made a trial instrument.

\section{Development of an instrument for making chromosome slides}

We have now a trial product named "Chromosome Slide Processor". An outside view of the instrument and a schematic drawing for explanation of control systems are shown in Fig. 1. Automatic slide supplyer and technical key-points to spread chromosomes are shown schematically in Fig. 2.

1) Main characteristics of trial instrument

In Table 1, main characteristics are summarized. For slide processing under different conditions, three separate rooms made of transparent acryl plates were built up on the front-upper part of main body of instrument; first one for slide setting, the second for chromosome spreading, and the third for slide drying. Further detailed explanations for control systems of the instrument are described in the followings.

a) Temperature control system

In order to maintain constancy of room temperature and humidity, an air-conditioner was used only for the slide setting room. Except for this room, temperature control of other rooms

Table 1. Outline Features of "Chromosome Slide Processor"

1) Main Body Weight: $90 \mathrm{~kg}$ Size: $1,000 \mathrm{~mm}$ (width) $\times 650 \mathrm{~mm}$ (depth) $\times 530 \mathrm{~mm}$ (height)

2) Air Conditioner (accessories) Weight: $47 \mathrm{~kg}$ Size: $300 \mathrm{~mm}$ (width) $\times 500 \mathrm{~mm}$ (depth) $\times 700 \mathrm{~mm}$ (height)

3) Room for slide treatment

a) slide setting room $\left(3,540 \mathrm{~cm}^{3}\right)$, b) chromosome spreading $\operatorname{room}\left(540 \mathrm{~cm}^{3}\right)$, c) slide drying $\operatorname{room}\left(2,000 \mathrm{~cm}^{3}\right)$

4) Control System

a) Temperature: solid-state thermomodules (13 sets)

b) Humidity: air-bubbling in heat-controlled water

c) Mechanical relation: sequencers

5) Accuracy of controls

a) Temperature: $\pm 0.5^{\circ} \mathrm{C}$ (range, $20-50^{\circ} \mathrm{C}$ )

b) Humidity: $\pm 3 \%$ (range, $20-80 \%$ )

6) Other equipments

a) Automatic slide supplyer, b) Slide transfer system,

c) Digital indication of on time changes of temperature and humidity

7) Efficiency of slide production

one slide every 12 seconds 

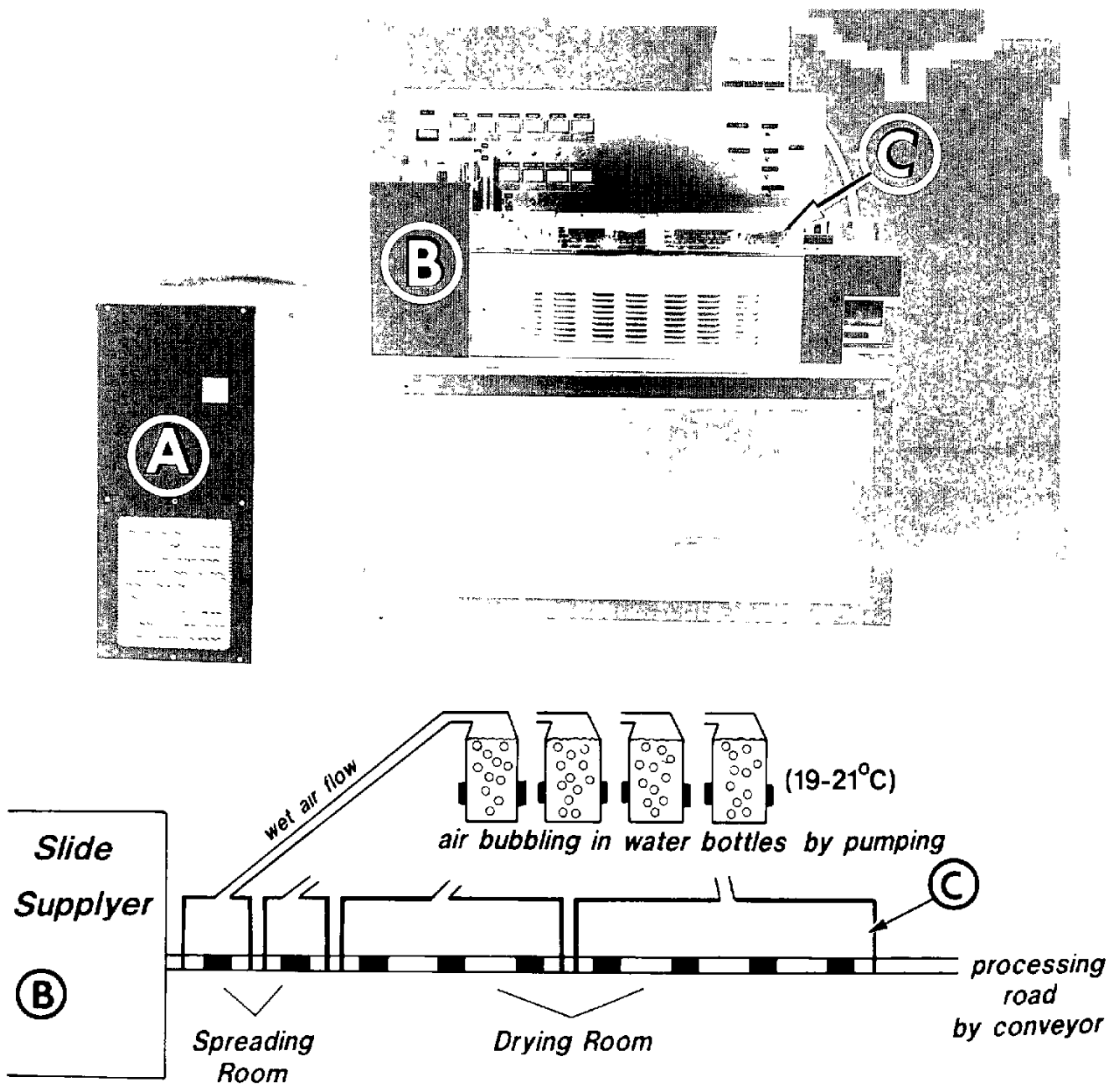

hot plate regulated by thermomodule

Fig. 1. Outside view of instrument (upper) and control systems of room temperature and humidity by thermomodules (bottom). A: an air-conditioner, B: slide setting room. C: separate rooms for slide treatment.

was performed by hot-plates regulated by solid-state thermomodules: A hot-plate of slide-glass size is regulated by two thermomodules, controlled by the feed-back system of sensors setting inside the room, and mounted in fixed places of the surface of slide processing road. A slide slipping on the road surface is stopped for a fixed time exactly on every hot-plate for slide treatment (Fig. 1). The spreading room has two hot-plates and the drying room has seven, so that a total of 18 thermomodules are used for controlling room temperature. The spreading room and drying room are further subdivided into two small compartments, respectively. 
Therefore, four compartments can be maintained, if necessary, in different ways in respect of room temperature and humidity.

b) Humidity control system

To produce wet air, four water-bottles each connected through a tube with a large water tank were placed in the inside of main body of instrument. Water temperature of each bottle was regulated by two thermomodules directly touching to the bottle wall (Fig. 1). Air with a mild flow ( 5 liters/minute) was moistened by bubbling in water with a constant temperature (a range of $19-21^{\circ} \mathrm{C}$, usually), and sent through a duct to a compartment room. Thus, the constancy of room humidity in each compartment was maintained by strict control of water temperature of the bottle and by a constant air flow.

c) Automatic slide supply and transfer system

The slide setting room has a slide basket with capacity of 50 slide-glasses, which is placed in the cage of an elevator (Fig. 2). Slide supply and transfer were done as follows: When the elevator moves down slowly pitch by pitch, every the lowest bottom slide in the basket is trapped with hooks of moving chains and sent one by one in regular interval on a straight road for slide processing. Slide move and stop in accordance with moving of two lines of chains underlying the processing road. Thus, slide were sequentially treated by just going along the road. On the end of the road, automatic slide receiver will be added by development in the next year.

2) Outline of slide preparation

For flattening and drying cells, slides smeared with cells were exposed to different atmosphere. Chromosome slides were obtained by the process described in the followings: First, slides in a slide basket were kept for a while in the slide setting room. The atmosphere of the room was maintained constantly to be $25^{\circ} \mathrm{C}$ temperature and $3-5 \%$ humidity. When a slide entered the spreading room, an aliquot (usually, 25-30 $\mu$ ) of cell-suspension was dropped as soon as possible from a $2-3 \mathrm{~cm}$ distance above the slide, by using a micropippete through a small injection hole of the ceiling of the room (Fig. 2). Slides were sloped at an angle of 10 degrees to spread cells far and wide on the slide surface. The atmosphere of the spreading room was maintained to be usually $32-35^{\circ} \mathrm{C}$ temperature and $45-60 \%$ humidity. After passing through the room, slides were gradually dried up in the drying room which had atmosphere of $45^{\circ} \mathrm{C}$ temperature and 20-30\% humidity.

\section{Results of chromosome spreading in the use of trial instrument}

1) Mechanism of chromosome spreading

For explanation on the mechanism of spreading cells and chromosomes on the slide surface, room conditions and technical procedures are shown in Fig. 2.

When an aliquot of cell suspension was dropped on a slide, the degree of wet condition of the slide surface was an important factor for spreading cells. By the above reason, slides are kept, at first, in the slide setting room with 3-5\% of low humidity. Then, a slide enters the spreading room, and the surface of the slide glass is quickly moistened and become wet for a moment by touching a hot air with high humidity, and soon become dry due to high temperature of the room. Therefore, it was necessary to drop a cell-suspension during a few seconds just after a slide entered the room. Scattering and spreading cells may be achieved by two strengths 


\section{Mechanism of Spreading Cells and Chromosomes}

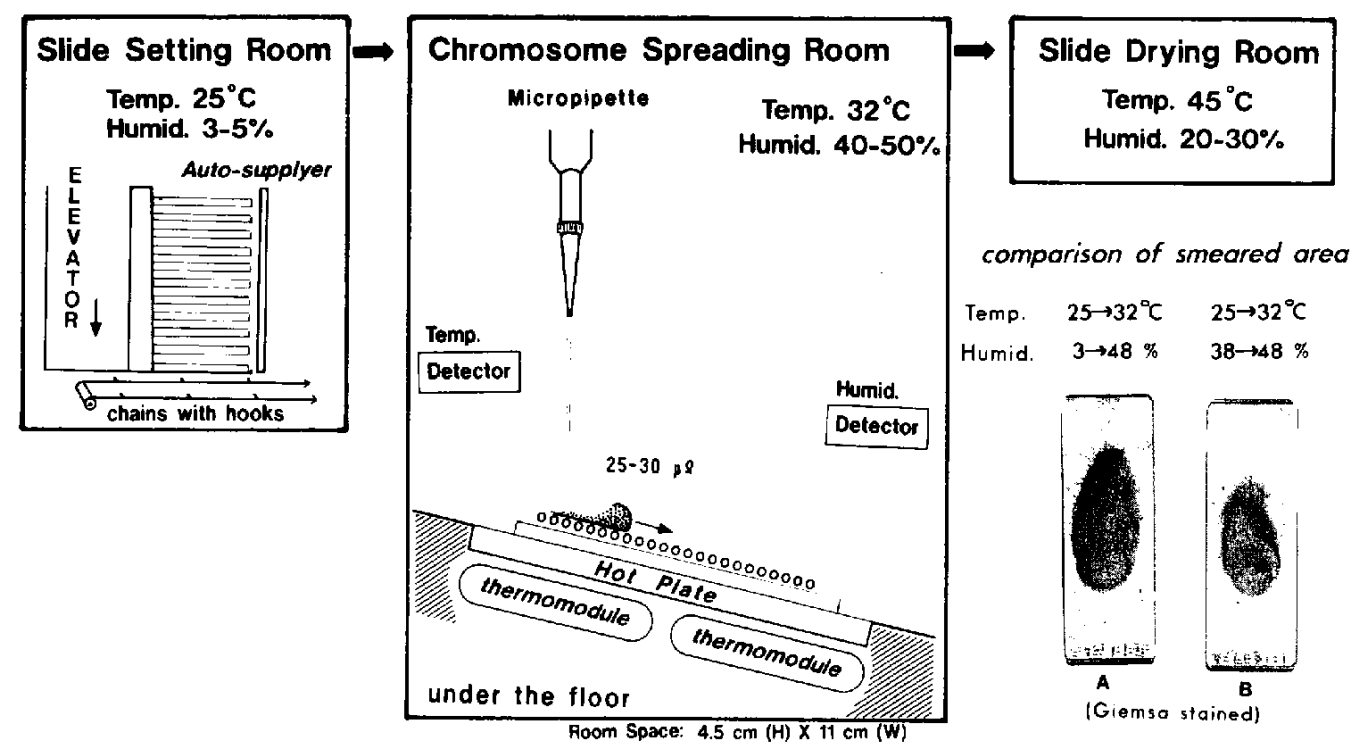

Fig. 2. Schematic drawing on mechanism of spreading cells and chromosomes (see text for explanation).

produced on the slide surface; one strength produced by rapid intermixing of cell-suspension and moisture attaching to the slide surface, and another produced downward along the slope of the slide by slipping down of cell-suspension. The degree of moisture attaching the slide surface may be adjustable by altering differences of temperature and humidity between the two rooms. In this instrument, differences of $7-10^{\circ} \mathrm{C}$ in room temperature and $40-45 \%$ in humidity seemed to produce fairly good results.

Another important factor which probably worked upon spreading chromosomes was the retention time of slides staying in the spreading room. Longer the retention time in the room showed a trend of over-spreading of chromosomes. The retention time seemed to be fairly good for 20-25 seconds. Alteration of the retention time according to the change of room conditions was needed. The retention time in the drying room was enough for $70-80$ seconds, giving no effect on chromosome spreading.

2) Effects of different cells and fixatives on chromosome spreading

From the present study, it was found that combinations of temperature, humidity, and retention time were delicate and critical to get good quality of chromosome spreads. In this respect, full-automation by a programmed pattern seemed to be fairly difficult. Moreover, effects on chromosome spreading seemed to be slightly different due to differences of fixed materials and fixatives. Results of the above analysis are shown in Table 2 . In this instrument, Carnoy's fixative containing methanol was found to be more apt to over-spreading of chromosomes in freshly fixed lymphocytes, fibroblasts, and amniotic cells cultured in vitro. 
Table 2. Results of Chromosome Spreading in Different Cells and Fixatives by the Use of "Chromosome Slide Processor"

\begin{tabular}{llll}
\hline \multirow{2}{*}{ Material } & \multicolumn{2}{c}{ Carnoy's fixative } & \multicolumn{2}{c}{$\begin{array}{c}\text { Fixative } \\
\text { recommended }\end{array}$} \\
\cline { 2 - 4 } & M A & E A & \\
\hline $\begin{array}{l}\text { Cultured lymphocytes } \\
\text { 1) freshly fixed }\end{array}$ & over-spread & well-spread & E A \\
2) stocked in freezer & well-spread & under-spread & M A \\
3) EB-transformed cell-lines & over-spread & well-spread & E A \\
\hline Cultured fibroblasts for a long term & over-spread & well-spread & E A \\
\hline Amniotic fluid cells, freshly fixed & over-spread & well-spread & E A \\
\hline Bone marrow cells, one day cultured & well-spread & under-spread & M A \\
\hline
\end{tabular}

MA; methanol : acetic acid $=3: 1, \mathrm{EA}$; ethanol : acetic acid=3:1. All experiments were done in similar conditions; hypotonic treatment of $0.075 \mathrm{~N} \mathrm{KCl}$ for 12 minutes, and atmosphere of chromosome spreading room with $32^{\circ} \mathrm{C}$ temperature and $45-48 \%$ hymidity.

However, in such cell materials slides with well-spread chromosomes were obtained either by fixing cells in Carnoy's fixative containing ethanol from the beginning, or by substitution with Carnoy's fixative containing ethanol at least 20 minutes before slide preparation.

In this study, it was found that slides with good quality of chromosome spreads were obtained rapidly and constantly in quality, by the use of a "chromosome slide processor".

\section{Future development}

This instrument must be improved in many respects particularly for easy handling and operation. Furthermore, additional functions showing in Table 3, will be developed in the coming years. This instrument will be completed as one of related instruments of the automated chromosome analysis system which has been under development by our project team ${ }^{8}$.

Table 3. Additional Functions by Future Development

1. Automatic slide receiver

2. Automatic cell-sample supplyer by micropipetting

3. Slide counting and identification system

4. Mechanical relations by micro-computer system

5. One body packing by reduction in size and weight

\section{ACKNOWLEDGEMENTS}

The authors express our thanks to Mrs. N. Arita for technical assistance. This study has been supported since 1989 by an Atomic Energy Research Grant (No. 13073-2123-09) from the Science and Technology Agency of Japan. 


\section{REFERENCES}

1. Sasaki, M. S. and Miyata, H. (1968) Biological dosimetry in atomic bomb survivors. Nature. 220: 11891193.

2. Awa, A., Sofuni, T., Honda, T., Ito, M., Neriishi, S. and Otake, M. (1978) Relationship between the radiation dose and chromosome aberrations in atomic bomb survivors of Hiroshima and Nagasaki. J. Radiat. Res. 19: 126-140.

3. Ishihara, T. and Kumatori, T. (1983) Cytogenetic follow-up studies in Japanese fisherman exposed to fallout radiation. In "Radiation-Induced Chromosome Damage in Man", Ed. T. Ishihara and M. S. Sasaki, pp. 475-490, Alan R. Liss, New York.

4. Melnyk, J., Persinger, G. W., Mount, B. and Castleman, K. R. (1976) A semi-automated specimen preparation system for cytogenetics. Proceeding of automation cytogenetics, Asilomar Workshop, pp. 51-67, U.S. Department of Commerce, National Technical Information Service, Conf-751158.

5. Vrolijk, J., Korthof, G., Vletter, G., van der Geest, C. R.G., Gerrese, G. W. and Pearson, P. L. (1989) An automated system for the culturing and harvesting of human chromosome specimens. In "Automation of Cytogenetics", Ed. C. Lundsteen and J. Piper, pp. 135-148, Springer-Verlag, Berlin, New York.

6. Martin, A. O., Shaunnessey, M., Sabrin, H., Maremont, S., Dyer, A., Cimino, M. C., Rissman, A., McKinney, R. D., Cohen, M. M., Jenkins, E. C., Kowal, D. and Simpson, J. L. (1989) Evaluation and development of a system for automated preparation of blood specimens for cytogenetic analysis. In “Automation of Cytogenetics", Ed. C. Lundsteen and J. Piper, pp. 149-173, Springer-Verlag, Berlin, New York.

7. Rothfels, K. H. and Siminovitsch, L. (1958) An air-drying technique for flattening chromosomes in mammalian cells grown in vitro. Stain Tech. 33: 73-77.

8. Hayata, I., Yamamoto, M., Yamada, K., Tomita, S. and Okabe, N. (1990) Development of a high-speed automated system for analyzing radiation-induced chromosomal aberrations. Radiol. Sci. 33: 369-371 (in Japanese). 